\title{
The Existence of Culture in its Relevance to the Dynamics of Globalization: Bahasa Indonesia Case Study
}

\author{
Iskandarsyah Siregar \\ Head of Nusantara Socioculture Studies, Universitas Nasional, Indonesia
}

$\square$ Corresponding Author: Iskandarsyah Siregar, E-mail: regaranggi@presidency.com

\author{
ARTICLE INFO \\ Received: 11 September 2021 \\ Accepted: 16 October 2021 \\ Published: 26 October 2021 \\ DOI: $10.32996 /$ ijcrs.2021.1.1.5
}

\section{KEYWORDS}

Existence, Culture, Bahasa

Indonesia, Globalization.

\section{ABSTRACT}

Language is present as a form of crystallization of the values of civilization and mediating and directing the orientation of the movement of civilization. Therefore, language becomes an important and interesting variable to be studied and revised scientifically for the preservation and progress of civilization. The Republic of Indonesia has an official language used by its citizens, namely Bahasa Indonesia. This language aims to unite the Indonesian people who are multicultural or have ethnic and cultural diversity so that no distance separates fellow Indonesian citizens from hundreds of tribes, according to the 1928 Youth Pledge Convention. The thing that must be realized now is the use of the Indonesian language which is getting weaker. The weakness is not that it is not used at all but that foreign terms are included in public discussion, and it tends to be considered more prestigious to be used. This study uses a descriptive qualitative method that refers to the sources of literature and the results of previous studies. The existence of Indonesian can decline when most Indonesians are happy and proud to use a foreign language that is considered more respectable and classier. However, the current condition of the existence of the Indonesian language is still in a safe stage. Bahasa Indonesia can continue to exist while preserving it by following the prevailing context and linguistic rules and developing its construction according to the needs and desires of civilization.

\section{Introduction}

\subsection{Preliminary}

Language is an exciting entity to be studied and questioned. Its existence which is vital to civilization though often underestimated makes it necessary to decide right or wrong. Language is a means of conveying messages from articulators to auditors (Siregar, 2021 , p. 54). Culture is a manifestation as well as forming civilization. Likewise, language. Language is present as a form of crystallization of the values of civilization and mediating and directing the orientation of the movement of civilization. Any variables that try to be present in civilization must go through an intermediary called language. Therefore, language becomes an essential and exciting variable to be studied and revised scientifically for the preservation and progress of civilization. Language is also recognized as a system of sound symbols used by humans to communicate in everyday life. The sound symbol in question is a sound symbol that has meaning to something or the context of the referred referent. The use of language becomes meaningful if the speaker can convey the message correctly and adequately to the speech partner. The speech partner can also catch the message intended by the speaker so that he can respond to the message correctly and adequately.

The Republic of Indonesia has an official language used by its citizens, namely Bahasa Indonesia. This language aims to unite the Indonesian people who are multicultural or have ethnic and cultural diversity so that no distance separates fellow Indonesian citizens from hundreds of tribes, according to the 1928 Youth Pledge Convention (Sumpah Pemuda 28 Oktober 1928). Therefore, a country that has decided to use Bahasa Indonesia as an official language should continue socializing its excellent and correct

Copyright: (C) 2021 the Author(s). This article is an open access article distributed under the terms and conditions of the Creative Commons Attribution (CC-BY) 4.0 license (https://creativecommons.org/licenses/by/4.0/). Published by Al-Kindi Centre for Research and Development, London, United Kingdom. 
use to all Indonesian people, domestically and abroad. The ultimate goal of using Bahasa Indonesia is to instill excellent and correct Bahasa Indonesia skills and foster an attitude of love for the homeland by proudly using Indonesian.

The thing that must be realized now is the use of the Indonesian language, which is getting weaker. The weakness is not that it is not used at all but that foreign terms are included in public discussion, and it tends to be considered more prestigious to be used. It is undeniable that the inclusion of foreign terms can enrich the language's vocabulary, but it can still be a concern for the existence of Indonesian in the future. In addition, the inclusion of foreign terms is because people are interested in using them rather than terms native to Bahasa Indonesia.

English is one of the languages widely absorbed into the vocabulary in the Big Bahasa Indonesia Dictionary (KBBI). Absorption by using the stages that have been arranged sequentially. These stages start from adopting, adapting, to translating. The best stage is the translation stage because this stage is the same as purifying the vocabulary from foreign terms into new terms in Bahasa Indonesia. In addition, the influence of the English language is also due to its plural use throughout the world.

Research and discussion about the existence of the Bahasa Indonesia have been widely circulated globally in the network. The study's conclusion of the existence of the Bahasa Indonesia is that environmental factors can influence the use of the Indonesian language, both used correctly and adequately or distorted into non-standard forms (Murti, 2015; Rahayu, 2015; Santoso, 2018). Language as identity and national identity must be maintained by prioritizing Indonesian over foreign languages such as English. Thus, the impact that will be caused is that the feeling of love and pride for Indonesian language users increases. The purpose of this study is to show the results of the study of reference sources regarding the existence of the Indonesian language in society, the manifestation of the character of the Indonesian nation, the primary role of the Indonesian language, the supporting role of English, and the importance of Bahasa Indonesia in the realm of education of globalization situation.

\section{Research Methodology}

Each research has its characteristics. There are quantitative studies that use accurate calculations. There is also qualitative research that emphasizes the quality of data sources as the object of research. The two characteristics of the research have one goal: to prove problems, theories, and previous studies and produce the latest findings of the subject being worked on.

This study uses a descriptive qualitative method that refers to the sources of literature and the results of previous studies. Qualitative research studies the object as a whole, not specifically identifying one or more variables from the object (Budiyono, 2017). The purpose of this study is to process old materials along with the latest reference sources and the latest studies into new results.

\section{Results and Discussions}

\subsection{The Existence of Bahasa Indonesia}

The formation of the Indonesian language did not happen immediately. There is history to be discussed in it. Its history begins with Malay as the mother tongue. Then it became a lingua franca that was spread throughout the countries it visited, one of which was Indonesia. After an extended period, Malay finally turned into Indonesian as the national language seen in Susanto (2016). Next, as the national language and the language of the state. Finally, Bahasa Indonesia entered into the development period as the language of culture and science.

Until now, Bahasa Indonesia is still under construction. People are still taught how to speak correctly and adequately. This language continues to grow and develop in line with the growth of the Indonesian nation. Moreover, being designated as the language of culture and science, Indonesian already has a respectable place to be adequately studied. Everyone can know and learn it because Bahasa Indonesia does not limit itself to specific circles.

At first, Indonesian was poor vocabulary, which did not have many words and terms in the dictionary. However, after independence was proclaimed, the Indonesian language was no longer poor. Many new words, new terms, and so on grow and develop rapidly over time. Of course, the new vocabulary and terms emerged after being absorbed from a foreign language. English is becoming more absorbed than other languages.

One of the existences that Bahasa Indonesia wants to show is its position as a national language. During its growth and development, Indonesian received many elements or influences from regional languages (Javanese) and foreign languages (English). The strong influence of other languages on Indonesian makes the absorption of foreign terms inevitable.

Foreign terms that enter the community are used more than domestic terms. The reason for using foreign terms is because many people like and try foreign languages. Foreign terms that have flooded the minds and hearts of every user have also spread to the stage of being used in public spaces. Use in city public spaces such as billboards, billboards, and pamphlets. The use of the term does not only occur in cities but also in villages. Even though the foreign terms in question are also available in Indonesian. 
The pride of the Indonesian people towards foreign languages such as English rather than Indonesian itself is very worrying. Especially for English users among non-academics or the general public. If this is allowed, it is not impossible if one day the Indonesian language is forgotten. Therefore, scholars are obliged to overcome this problem and continue to spread the Bahasa Indonesia that is good, correct, and appropriate.

During the Japanese occupation, the existence of the Indonesian language was evident. Its existence was marked by the establishment of the Indonesian Language Commission. At that time, it began to create many new vocabulary or terms useful in science and today's life. The main task that became the initial task of the Indonesian Language Commission was to be able to record standard grammar.

Indonesian must remain the national language used by the community with applicable rules. The most basic Indonesian language development takes place in schools and is most common in the community. This preservation and habituation are expected to make people aware of the importance of the Indonesian language as a national identity.

A basic understanding of science can be a solid foundation to strengthen the next stage of science. Likewise, with the Indonesian language, if a nation can master the basics of knowledge, the Indonesian language will remain forever.

Errors in speaking Indonesian are unavoidable. This is still understandable if the error occurs temporally with a small amount. In addition, errors can also occur if the user makes a mistake or makes a mistake in choosing words or terms.

However, problems become unnatural when mistakes are made repeatedly, and language users do not want to admit their mistakes. Of course, this becomes difficult to resolve. This error is no longer made unconsciously, but there is an error in language users who do not want to admit their mistakes and do not want to learn from them.

Education of character education is essential to be implemented in this country of Indonesia. The nation's generation needs to be nurtured continuously so that they can appreciate the process during learning. One of them is that the character is responsible for the mistakes made and is willing to discipline himself to learn so that the knowledge received is entered into the mind and can also be lived in the heart and practiced in real life.

The character of a nation plays a significant role in maintaining its existence and independence (Zusnani, 2012). Based on the results of a study by Bakar, Noor, and Widodo (2018), character education is beneficial so that people do not get lost in their future. A straightforward life goal can guide a person's success in every processor stage he goes through.

National character is helpful as an identity so that it is easily recognized. The swift currents of globalization must be watching for not being too caught up in these currents. People who have a strong character, no matter how intense the currents in this global era are, can still survive to be themselves. People with character can contribute to enriching the current with their characteristics and uniqueness.

Efforts need to be made to stem the global flow of free-flowing people with weak character. People belonging to this generation must strive to improve themselves to form and strengthen their identities. The following are the roles that the younger generation can play, namely: (1) as a character builder, rebuilding the positive character of the nation with a strong will and commitment to upholding moral values above temporary interests as well as being applied in their daily activities; (2) as a character enabler, the firm will consist of the younger generation to become a role model for the development of a positive national character; and (3) education as a place for forming national insight, namely changing the mindset of citizens from ethnicity to being a complete nationality (Zusnani, 2012).

Indonesian can be an identity that shows the character of the nation. The condition is by studying the context and the rules of the Indonesian language thoroughly and studying the culture of literary works as described by Rondiyah, Wardani, and Saddhono (2017). Learning becomes effective and efficient when you already know the basics first. Thus, the expected result of the overall Indonesian language learning process is the skill to master the main points of Indonesian teaching while at the same time creating the character of a profound, disciplined, visionary, and responsible learner.

Discipline is a person's attitude in managing time and opportunities as well as possible consistently. This attitude is formed because a person tends to prioritize the applicable rules over contexts that are still vague. In addition, the discipline also educates one's self to be a person of character and intelligent in making decisions.

Discipline in Indonesian is an advanced stage of good language habituation. The obligation contained in this disciplinary attitude is to pay attention to the correctness of the language used after speaking well, as explained by Zamzuri (2017). This attitude applies to all Indonesian language users, especially to intellectuals and teachers.

Disciplined language users will show the quality of their language from spoken and written aspects. The oral aspect is skilled in speaking and listening. The writing aspect is writing and reading. The fewer pronunciation errors that are spoken and the lower the level of incorrect writing, the more disciplined a person will be in the language. 


\subsection{The Main Role of Indonesian}

The beginning of the Indonesian language was legalized on October 28, 1928. Since then, Indonesian has been popularized in the Unitary State of the Republic of Indonesia as the national language and the state's official language. The reach of the Indonesian language must be able to cover the entire country so that unity can occur among Indonesian citizens. Thus, Bahasa Indonesia has a very important position (Murtiani, Arifah \& Noviastuti, 2017).

As a unified language, Bahasa Indonesia is one of the ropes that bind us to become one Indonesia (Rosidi, 2015). However, the area of distribution of this unified language is still not evenly distributed. There are still many people who use their respective regional languages, especially in remote areas. This is still not in line with the decision of one of the statements in the Youth Pledge, namely, "... in one language, Indonesian." The purpose of speaking one language here is the aspiration to realize a unified language.

Limitations in accessing languages can be overcome by building and improving infrastructure. Heavy terrain that hinders and inadequate facilities are gradually reduced. It is hoped that communication between citizens between regions: city/regency to city/regency, village to village, and village to city/regency, and vice versa, can run smoothly and open vast opportunities for the distribution of the Indonesian language.

Mastery of science, such as procedures for building a village and connecting the village to the city, requires skilled and skilled personnel. The best way to produce such experts is through education. Humans are educated so that they can become valuable people for the surrounding environment, especially families.

Information about development can be obtained if you study and understand Bahasa Indonesia correctly and adequately. The ability to master language skills is beneficial for obtaining information and broadening the insights obtained from various sources of print media (books, newspapers, magazines, bulletins, banners, billboards, etc.), electronic media (television, radio, megaphones)., etc.), and online media (news portals, social media, messaging apps, etc.). Therefore, everyone should understand Indonesian, even if it is only the basics.

Today, electronic devices to receive information such as television and radio are very easy to find. These devices are produced with various kinds of innovations and variations. There is tube television - it is rare; flat-screen televisions, cable radios, portable radios, etc. All of that is provided as an option for buyers. What is more, friendly prices do not prevent buyers from owning these devices.

If you still cannot have these devices, take the example of television, then you do not have to worry about it because information can still be obtained through the village head's office for villagers or the sub-district office for residents of a sub-district. Understanding information from television requires listening and reading skills on the television screen. If you cannot master (at least) these language skills, then it is possible that your understanding of a news broadcast will be lacking. Therefore, understanding Indonesian is a very urgent need to be understood quickly.

The emergency of understanding Indonesian must be handled immediately with gradual counseling. Lessons that can be learned in extension activities are listening, speaking, reading, and writing. At first, the counseling activity was a reading and writing ability test for each instructor. If you have mastered it, the ability to read a light discourse becomes the next learning activity.

Next is the practice of speaking, telling stories, and giving speeches. The activities consist of a question and answer language instructor with language instructor; the appearance of a group of tens of thousands to have a conversation in front of the participants with a predetermined theme. Performing in front requires courage. This is where the role of the instructor guides the errand boy to be brave or appear confident.

Extension workers also teach the ability to read. It is hoped that the village will have a library that provides light reading books and newspapers. The purpose of building a library is to awaken the villagers' reading craze. The supply of books can be obtained from the involvement of the library and publishers in supporting the construction of libraries in the village.

Generating a passion for writing for rural people aims to develop the ability to write their ideas and ideas concerning the needs of daily life and the desires to be achieved, not just understanding writing. The habit of writing is expected to keep activities that are less effective and efficient in daily activities to get used to writing neatly stored. If the writing habituation activity is successful, the writing program will proceed to the next stage: making various kinds of notes, announcements, and writing letters.

English has been used by the British since a dozen centuries ago, but Indonesian was only used by Indonesians not a hundred years ago (Chaer, 2002). Until now, English is still widely used as an international communication tool. Bahasa Indonesia is still new than English. However, that does not mean that Bahasa Indonesia does not have its sovereignty.

Nowadays, many people prefer to use English. English's good use promises a much better socio-economic status and level than just mastering Indonesian (Chaer \& Agustina, 2014). There are many reasons they use English. There is a reason because of the demands of work abroad. There is also a reason that the surrounding environment uses English writing a lot. There is also a reason 
because English is more excellent than Bahasa Indonesia. The latter reason is worrying and has consequences, as explained by Fajar (2016).

The difficulty of avoiding the use of English is actual. English, which has existed for centuries, is often present in human life in many ways. These roads include advertisements, articles, products, services, and most often, devices and the internet.

Nevertheless, English, which is the primary international language, should not be a reason to obscure the existence of Indonesian as a national identity. Indonesian must remain victorious in this motherland. The trick is to preserve it according to the context and applicable rules. Then, familiarize and teach it to everyone, especially Indonesians. If foreign speakers in Indonesia learn Indonesian, they have to go through many obstacles, as contained in Saddhono's research (2012), then native speakers or Indonesians should minimize this, coupled with a solid intention to learn.

Do you remember the phrase, use Indonesian correctly and adequately? These expressions are not just words but contain deep meaning. Indonesian is spoken in a good way according to the context and following the rules or rules that apply. Thus, the existence of the Indonesian language will never fade.

English should be used as a language that supports Indonesian only. For example, finding a word in English whose absorption is known or the original language in Indonesian, then putting the Indonesian word first before the English word. English is only used as a comparison when Indonesian requires references in English, so the keywords are prioritized.

Education is a necessity that is essentially crucial because it is directly related to the realm of human life (Zusnani, 2012). Avoiding education is the same as weakening one's condition and keeping away from the source of knowledge. In addition, the relationship between teachers and students is not good in terms of morals. The moral teachings need to be considered according to Wahid \& Saddhono (2017). Therefore, education is something that is needed by every human being.

Education is the right path to spread knowledge of the Indonesian language. The reason is that Indonesian should be learned in school as a second language after mother tongue. In addition, students can imitate the appropriate Indonesian language from the teacher of the subject in question.

Educators and education staff are critical factors in implementing the learning process in academic units (Subijanto et al., 2017). The responsibility of a teacher, especially the Indonesian language teacher, is enormous in educating students to speak Indonesian correctly and adequately. The teacher becomes a model for the students to emulate. The teacher's language is certainly not a language with a set of foreign words and areas difficult for students to understand. Moreover, the teacher's language is neither a dialect nor the language of the print media. Therefore, teachers are expected to be careful in teaching Indonesian to their students.

Today, oral and teacher behavior matters that can affect the Indonesian language learning process are not given much attention, generally caused by forgetting when teaching in a passionate style. Often there is a verbal utterance that is wrong, not per the correct structure.

The realm of education is the right place to teach sound and correct Indonesian. According to Rahayu (2015) in his research said that there are five steps to prevent and overcome the Indonesian language before it is entirely extinct, namely:

1. making educational institutions the basis for language development,

2. the need for a good and correct understanding of the Indonesian language,

3. it is necessary to have a linguistic law,

4. the role of language variations and their use, and

5. uphold the Indonesian language in their own country.

Indonesian language development must start from school. A place to gain knowledge with the guidance of teachers and an atmosphere of learning with friends makes communication often occur between individual students, friends, and teachers. The Indonesian language teacher should start the best use of Indonesian. The reason is that the teacher in question already knows the knowledge he teaches in college or even before that. In essence, the Indonesian language teacher becomes a role model for the students he teaches.

Apart from the teacher, students are also responsible for the knowledge of the Indonesian language that has been obtained from the teacher at the school. When students make mistakes in language, students should not silence their mistakes. Mistakes that are allowed to continue can harm students and the surrounding environment. Although the teacher may know which students do not understand, the teacher will appreciate students who are active in asking for an explanation of the material that has not been understood.

\section{Conclusion}


Bahasa Indonesia was born as a mutually agreed language by the Indonesian people from hundreds of tribes. When designated as the language of culture and science, interest in learning the language is getting higher. However, the existence of Indonesian can decline when most Indonesians are happy and proud to use a foreign language, such as English, which is considered more respectable and classier. Bahasa Indonesia can continue to exist while preserving it by following the prevailing context and linguistic rules and developing its construction according to the needs and desires of civilization.

As its status as the primary language of the Indonesian people, the spread of Indonesian must be comprehensive to all corners of the country. Mastery of the Indonesian language is crucial for all Indonesian citizens, especially those who live in villages. Obtaining information from electronic devices still requires language understanding. There is training from Indonesian language instructors to villagers as instructors. The activities consist of talking, telling stories, giving speeches, reading, and writing.Indonesian language teachers' guidance is essential because students can imitate every teacher's speech and behavior. Students also get appreciation from the teacher if they are serious in studying, especially.

However, the current condition of the existence of the Indonesian language is still in a safe stage. However, it is necessary to keep special attention to maintain Bahasa Indonesia, vocabulary, and the value of meaning, from loss or even extinction. The key is how these language rescuers move faster than globalization. Thus the Indonesian language will survive the heavy intervention of globalization and even color the globalization of civilization itself.

\section{References}

[1] Alwi, H. (2000). Indonesian in the Era of Globalization: Consolidating the Role of Language as a Tool for National Development. Jakarta: Center for Language Development and Development of the Ministry of National Education.

[2] Arifin, A. (2010). Carefully in Indonesian. Jakarta: AKAPRES.

[3] Artini, L. (2013). "The Use of English as Medium Of Instructions (Emi) and its Consequences on the Learning Process in View from Students' Perceptions". Journal of Social Sciences and Humanities, 2 (1).

[4] Chaer, A. (2013). Indonesian language development. Jakarta: Rineka Cipta.

[5] Mursidi K. (2008). The existence of Indonesian as a Unity Language. Journal of Social Humanities, 1(2), 172-184.

[6] Marsudi \& Zahrok, S. (2015). Loyalty in Indonesian is Questioned in the Era of Globalization. Journal of Social Humanities, 8(1), 95-105.

[7] Muslich, M. (2012). Indonesia in the era of globalization: position, function, guidance, and development. Jakarta: Earth Literacy.

[8] Saddhono, K. (2012). "Sociolinguistic Study of Foreign Students' Language Use in Indonesian Language Learning for Foreign Speakers (BIPA) at Sebelas Maret University". Linguistics and Literary Studies, 24 (2), 176-186.

[9] Saddhono, K. (2014). Introduction to Sociolinguistics: Theory and Basic Concepts. Surakarta: LPP UNS

[10] Siregar, I. (2021). Verbal Communication of Schizophrenic Patients Due to Neurotransmitter Distortion. QALAMUNA: JurnalPendidikan, Sosial, Dan Agama, 13(2), 543-556. https://doi.org/10.37680/qalamuna.v13i2.1037

[11] Siregar, I. (2020). Exploration and Implementation of the Cultural System as a Solution to National and State Problems. http://repository.unas.ac.id/id/eprint/811

[12] Siregar, I. (2021). Analysis of Betawi Language Interference on the Morphology of Adolescent Speech in Jakarta. Journal of Humanities and Social Sciences Studies, 3(8), 54-60. http://doi.org/10.32996/jhsss.2021.3.8.7

[13] Yahya, M., Andayani, \& Saddhono, K. (2018). The Relationship between Vocabulary Mastery and Diction Errors in Indonesian Sentences for Academic Level BIPA Students. Journal of the Creed, 1(2), 53-70. 